Certification of Completion of Item 2 of ASC FY07 Level-2 Milestone ID \#2380

D. A. Lipari

April 3, 2007 
This document was prepared as an account of work sponsored by an agency of the United States Government. Neither the United States Government nor the University of California nor any of their employees, makes any warranty, express or implied, or assumes any legal liability or responsibility for the accuracy, completeness, or usefulness of any information, apparatus, product, or process disclosed, or represents that its use would not infringe privately owned rights. Reference herein to any specific commercial product, process, or service by trade name, trademark, manufacturer, or otherwise, does not necessarily constitute or imply its endorsement, recommendation, or favoring by the United States Government or the University of California. The views and opinions of authors expressed herein do not necessarily state or reflect those of the United States Government or the University of California, and shall not be used for advertising or product endorsement purposes.

This work was performed under the auspices of the U.S. Department of Energy by University of California, Lawrence Livermore National Laboratory under Contract W-7405-Eng-48. 


\title{
Certification of Completion of Item 2 of ASC FY07 Level-2 Milestone ID \#2380
}

\author{
Donald A. Lipari \\ March 28, 2007
}

This report documents the completion of Item 2 of the three milestone deliverables that comprise Milestone ID \#2380: Deploy selected Tri-Lab resource manager at LLNL and develop support model. Specifically:

LLNL will integrate and support a commercial resource manager software product at LLNL to be used across the tri-lab HPC facilities.

Required tasks include the following two sub-items:

1. Integrate chosen tri-lab resource manager software product on at least one major computing resource at LLNL by end of Q2.

2. Develop a support plan that defines the roles and responsibilities between the tri-labs and the vendor for delivering a complete resource management solution. This plan will address the installation, configuration, and maintenance of the vendor's product; the vendor's responsibility to provide features that the tri-labs require; and the vendor's obligations to resolve problems encountered with the use of their product. This plan will also include a method for prioritizing the needs of the tri-lab facilities to ensure that the support the vendor provides is directed toward the greater good for the tri-labs. The support plan is to be drafted and approved by end of Q1. Los Alamos and Sandia will deploy this tri-lab resource manager in FY08.

The following sections in this report present the evidence of the completion of sub-item 1. Sub-item 2 has been previously delivered under the UCRL-AM-226917 document entitled: “Tri-Lab Support Model for Computing Resource Workload Management”.

\section{Historical Review}

The RFP for the Tri-Lab resource manager was issued on June 28, 2006. Tri-Lab representatives evaluated the bids in the weeks that followed. On July 28, 2006 the winning bidder was announced to be the Moab Workload Manager from Cluster Resources, Inc (CRI). 
System administrators from three labs spent the next few weeks evaluating Moab to ascertain whether it met the requirements stipulated in the RPF. By September 15, all three labs had formally issued their acceptance of Moab.

On September 18, 2006, the Tri-Labs formally accepted Subcontract \#B560474 with CRI and authorized payment in full to CRI of the invoiced amount.

Starting in September, members of the Integrated Computational Resource Management Group (ICRMG) within the Services and Development Division at LLNL began planning for the installation of Moab on the selected major computing resource, the 9216processor Atlas machine. During the months that followed, this group studied the capabilities of the Moab product and decided how to configure it to blend into the Livermore Computing environment.

There were two areas of intense activity. The decision was made to deploy the SLURM resource manager, also developed by the ICRMG, to be the underlying resource manager for Atlas as it is for every other high performance computing system within ICCD. Much work needed to be done to enhance and tailor the integration of Moab with SLURM.

The other major focus of activity was in creating and implementing the plan to support

Livermore Computing users who had amassed years of expertise and scripts in submitting their jobs to LC's existing workload manager, the Livermore Computing Resource Management (LCRM) System. While we knew users would have to ultimately learn how to submit their jobs to Moab, we needed to provide them a transitional solution to submit their jobs to Moab and status them using LCRM-like commands and working under the LCRM environment.

\section{The Tri-Lab Support Model}

The second sub-item from item 2 from the Milestone ID \#2380 calls for the creation of a Tri-Lab support model to define the working relationships between members of the three labs and the vendor, CRI. This document defines the policy and procedures for working together to configure Moab, create common conventions, tools and utilities, share expertise, report problems to the CRI, and drive the future enhancements and product develop of Moab to suit the Tri-Lab’s collective needs.

This document was finalized and, as noted above, approved by the Q1 deadline prescribed in item 2, and released as UCRL-AM-226917. http://www-r.llnl.gov/icc/sdd/icrm/Tri-Lab_WM_SupportModel.pdf

Following the procedures defined in the support model, the Tri-Lab Resource Management Board (TLRMB) was formed in January 2007. The first quarterly meeting of the TLRMB was held (via conference call) on January 10, 2007. The hosting rotation was decided and Livermore was made the host for the first quarter of CY07. Minutes of that meeting were released as: UCRL-MI-229337. 


\section{Milestone ID \#2380, Item 2, Sub-Item 1 Deliverables}

The following summarizes the products that were delivered to satisfy the requirements of the installing the chosen Tri-Lab resource manager on a major computing resource at LLNL.

\section{Moab Configuration and Installation}

The Moab Workload Manager is a very complex and versatile system. It would have been easy to install it out-of-the-box on LC computing resources using the default settings. Such a system would have presented a significant challenge to LC users as they learned to use not only a whole new set of commands, but operate under a substantially new paradigm as well.

The commitment was made to configure Moab to reflect the model and constructs that LC users were used to from their years of using LCRM. This required a careful analysis of just what LCRM was doing and finding the most optimal ways of configuring Moab to perpetuate this service and performance. The following products were created in support of this effort.

\section{Moab Administration Guide}

This guide documents all of the decisions made in the setup and configuration of Moab to suit the needs of the Livermore and Tri-Lab community.

\section{Moab Source Control}

One of the core elements in the Tri-Lab Resource Manager statement of work was the requirement that the vendor provide the full source code for their product. CRI provides and we download and archive daily updates to the code to our own source code version control repository. This safeguards the source code from public access and provides us a platform to create the install packages for the various machines across the Center.

\section{Redhat Package Manager}

Linux system administrators have come to rely heavily on using the Redhat Package Manager (RPM) mechanism for installing software onto production machines. CRI releases Moab to the Tri-Labs in source code format. It is up to us to compile this code and generate the binary executables for installation on our systems. We needed to take an additional step to create the RPM build procedure that packages the resulting Moab executables into an RPM package that we hand off to the Linux system administrators.

\section{Regression Test Suite}

We have written a comprehensive set of regression tests to run against all new builds we receive from CRI. We run these regression tests before we certify the builds for installation on production machines. 


\section{User Documentation}

While CRI has extensive Moab user training information on their web site, we wanted to offer LC users more customized information based on our unique configuration decisions. Hence, we wrote the following guides to help them to come up to speed on Moab.

Moab Quick Start Guide (UCRL-SM-228870). http://www.llnl.gov/icc/sdd/icrm/QuickStartGuide.pdf

This is a five page document that provides the essentials to getting jobs running under that Moab Workload Manager.

Moab at LC User's Guide (UCRL-WEB-228716) http://www.llnl.gov/LCdocs/moab/

This is a more detailed look into the various activities in running jobs through Moab that is tailored to a Tri-Lab user.

\section{User Assistance in Transitioning to Moab}

With the stated goal of standardizing the environment for submitting jobs across all three labs using Moab, we wanted to facilitate user adoption of the native Moab command set. We wrote the following guides to help users convert their existing LCRM job scripts to be Moab compliant.

psub To msub Translation Guide (UCRL-SM-228840) http://www.llnl.gov/icc/sdd/icrm/psubOptions.pdf

This chart summarizes options to the Moab job submission command (msub) that should be used in place of an option from the LCRM job submission command (psub).

\section{Icrm2moab Translation Utility}

This utility takes a legacy LCRM job script and converts it to a Moab-style job script.

\section{LCRM Compatibility}

With many users facing deadlines to run their jobs through the batch system, we needed to give them a way to continue in the short term to use the familiar LCRM commands. We therefore wrote a set of scripts that stand-in for key LCRM commands that interface to Moab but emulate the behavior of LCRM.

We also needed to emulate the LCRM library calls that user jobs were calling to receive running-time information. Again, we wanted to provide backward compatibility to the years of coding invested in LCRM. 


\section{The LCRM command wrappers}

These are six Perl scripts that emulate LCRM commands yet interact with Moab, making it appear to the user that they are still running their jobs under LCRM.

\section{Yogrt Library}

We wrote this library to work not only on Moab scheduled systems, but also on existing LCRM systems. The Yogrt Library provides a single programming interface that can compile and run anywhere, across LCRM and Moab, at Livermore and the other two TriLabs.

\section{LCRM Emulation Library}

We wrote the LCRM emulation library for those users who do not have the time to find and replace all existing calls to the LCRM library with Moab equivalents. This library interacts with Moab but emulates LCRM behavior.

\section{Options for LCRM Library Users (UCRL-SM-228839)} http://www.llnl.gov/icc/sdd/icrm/GetRemainingTime.pdf

This document explains the emulation of the LCRM libraries as well as the options available in using the Yogrt library.

\section{User Training}

A four-hour user training course was written for Moab and presented to the first set of users on March 14, 2007. The following are the two modules that were presented.

Moab User Training Presentation (UCRL-PRES-228869)

http://www.llnl.gov/icc/sdd/icrm/MoabUserTraining.pdf

Moab User Training (UCRL-PRES-228819)

http://www.llnl.gov/computing/tutorials/moab/

\section{Operator Training}

A training seminar with Moab information pertinent to the LC Operations staff was delivered to them on February $6 \&$ 7, 2007. The seminar content was uploaded to a web site maintained by the LC Operations Staff.

\section{System Administrator Training}

CRI's core Moab specialists delivered two day-long training seminars at Livermore (and broadcast to the other two Tri-Labs over the Access Grid) on December 19 \& 20, 2006. 
CRI's Moab Administration Presentation (CRI slides)

http://www.llnl.gov/icc/sdd/icrm/CRI_Training.ppt

\section{DVD of CRI's Presentation}

A video was made of CRI's presentation and has been released on DVD. The DVD has been distributed to system administrators who did not attend the training.

\section{Central Moab Information Web Page}

Most of the material described above has been placed in a central repository on the ICRMG website under a link entitled "Moab Information” and available to LC users and staff.

http://www.llnl.gov/icc/sdd/icrm/moab.html

\section{Functional Checklist}

What follows is a condensed list of Moab’s basic functionality we have tested and confirmed:

1. All Native Moab Commands Work

2. All LCRM Emulation Command Wrappers Work

3. Yogrt / LCRM Emulation Library Works

4. Job Usage Statistics Collected and Reported

5. User / Account (bank) Information Configured

6. Job, Host and Queue Limits Configured

7. Normal, Standby, and Expedite Job Classes Configured

8. Fair-Share Scheduling Enabled

9. Moab to SLURM Integration Complete 


\section{User Validation}

The following letter from is from key scientists who have run their jobs through Moab on Atlas and attest to Moab's readiness.

TO: $\quad$ LLNL ASC Office

FROM: $\quad$ Lin H. Yang

SUBJECT: Completion of LLNL ASC Level 2 Milestone 2380

DATE: $\quad$ March 21, 2007

As an LLNL application scientist asked to participate, I certify that the LLNL ASC Level 2 Milestone 2380, "LLNL will integrate and support a commercial resource manager software product at LLNL to be used across the tri-lab HPC facilities", was completed March 21, 2007 to my satisfaction. I certify that as of March 21, 2007 the Moab on Atlas system was usable and productive for my needs.

I have successfully run jobs on the Atlas machine using the Moab Workload Manager. I was able to submit jobs to the job queue, view job status, and run my jobs successfully to completion. I found that Moab scheduled my jobs to run in a suitable amount of time given the workload of the system.

In addition, I exercised the LCRM emulation commands to submit my jobs to Moab and receive status of my jobs from Moab.

The details of the LLNL efforts to meet this milestone are documented in the Certification of Completion of Item 2 of ASC FY07 Level-2 Milestone ID \#2380 report.

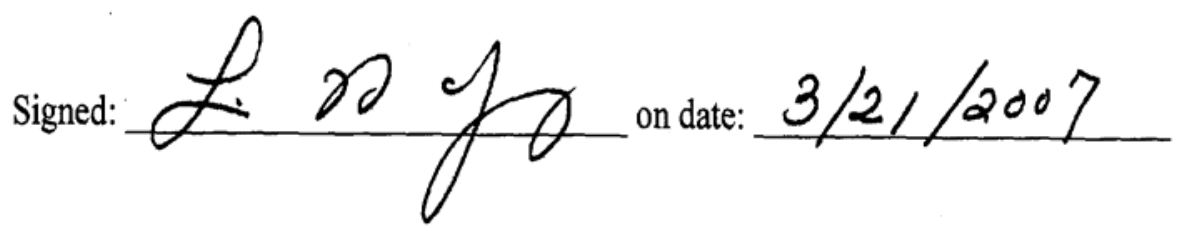




\section{Appendix 1 - Milestone ID \#2380}

Milestone (ID\#): Develop and deploy Tripod capabilities for capacity computing environment (\#2380)

Level: 2

Fiscal Year: FY07

DOE Area/Campaign: ASC

Completion Date: Jun-07

ASC nWBS Subprogram: Facility Operations and User Support (FOUS) \& Computational Systems and Software Environment (CSSE)

Participating Sites: LLNL, LANL, SNL

Description: The tri-labs will develop a coordination process and policies to deliver a seamless software environment for use by the NNSA tri-lab community (Los Alamos, Livermore and Sandia National laboratories), initially targeting Linux capacity computing clusters. The strategy has the following elements:

- Identify current and near-term production quality solutions, and develop a trilab migration plan to this initial environment.

- Identify tri-lab R\&D efforts focused on addressing gap areas, with acceptance criteria and an insertion plan for new technologies into the production stack.

- Develop and implement tri-lab update decision, acceptance, and deployment policies and processes to maximize state-of-the-art software capabilities, while minimizing operational disturbance.

The milestone deliverables are as follows:

1. Deploy limited set of Tripod components on selected capacity systems at all three labs:

The tri labs will provide, at a minimum, selected applications development tools listed on the project website: http:/ / tripod.ca.sandia.gov/under "ASC Project Milestones." Tasks required include: active participation in Tri-lab discussion of the essential common tools environment continues; Q3 deployment of current working version levels of the tool stack; appropriate documentation of user access methods for the tools and environment is made available to user; and procedures are in place for tracking, updating, and documenting version changes.

2. Deploy selected tri-lab resource manager at LLNL and develop support model:

LLNL will integrate and support a commercial resource manager software product at LLNL to be used across the tri-lab HPC facilities. Tasks required include: 1) Integrate chosen tri-lab resource manager software product on at least one major computing resource at LLNL by end of Q2; and 2) develop a support plan that defines the roles and responsibilities between the tri-labs and the vendor for delivering a complete resource management solution. This plan will address the installation, configuration, and maintenance of the vendor's product; the vendor's responsibility to provide features that the tri-labs require; and the vendor's obligations to resolve problems encountered with 
the use of their product. This plan will also include a method for prioritizing the needs of the tri-lab facilities to ensure that the support the vendor provides is directed toward the greater good for the tri-labs. The support plan is to be drafted and approved by end of Q1. Los Alamos and Sandia will deploy this tri-lab resource manager in FY08.

3. Produce a Tripod startup script at all three labs for prototyping:

Each lab will produce a startup script that could be used to put the tools that each site currently has licensed, and that are in the common toolset as per the Tripod tool list on Tripod web site, into a user environment on at least one machine at each site for prototype purposes. An additional follow-on deliverable will be documentation on how to use that environment and a simple user test of each lab's Tripod environment. Sites may go beyond prototyping if resources become available.

\section{Completion Criteria:}

1) Deployment of the capabilities listed above as the 3 milestone deliverables.

2) Completion of the definition of the next set of Tripod capabilities, along with a tri-lab policies and process plan for deployment.

\section{Customer: NNSA HQ}

Milestone Certification Method: Completion evidence will be (1) documentation and hand-off of the FY07 Tripod deployment on the tri-labs' Linux capacity computing platforms; and (2) a report detailing the decision, acceptance, and deployment policies for the next-generation Tripod capabilities.

\section{Supporting Resources:}

Codes/Simulation Tools Employed:

Contribution to the ASC Program: Common environments leverage resources and enhance user efficiency.

\section{Contribution to Stockpile Stewardship:}

\begin{tabular}{|l|l|l|l|l|}
\hline \multirow{2}{*}{ No. } & \multirow{2}{*}{ Risk Description } & \multicolumn{3}{|l|}{ Risk Assessment (low, medium, high) } \\
\cline { 3 - 5 } & & Consequence & Likelihood & Exposure \\
\hline & & & & \\
\hline & & & & \\
\hline
\end{tabular}

